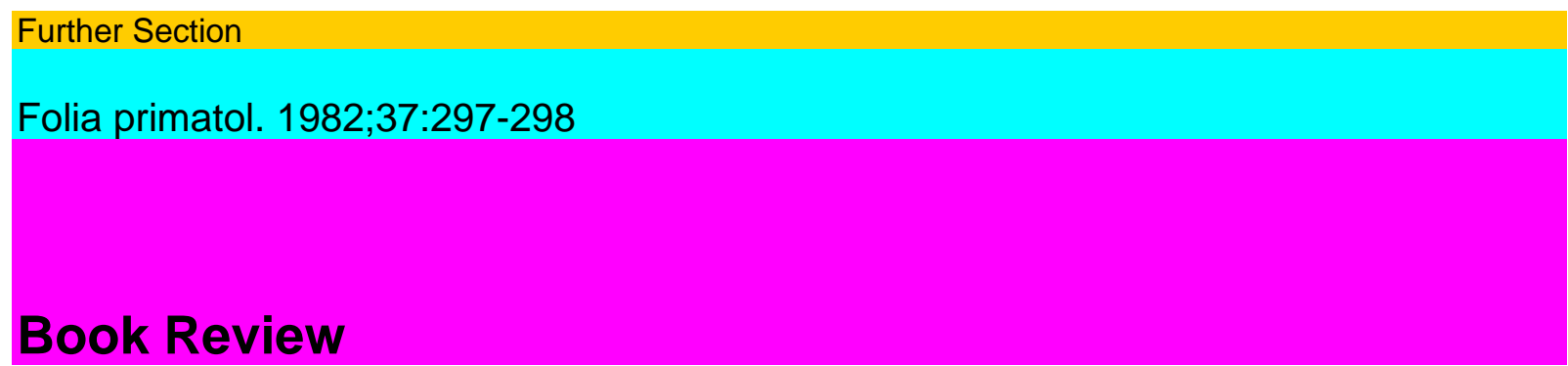

\title{
K. Milton
}

The Foraging Strategy of Howler Monkeys

A Study in Primate Economics Columbia University Press, New York 1980 XIV + 165 pp.; US \$ 25.00 ISBN 0-231-04850-5

This brief (165 pages) and well-written book results from Dr. Milton's 14 months studying the foraging strategy of the mantled howler (A. palliata) in Barro Colorado Island, Panama. The material used in the publication is part of her $\mathrm{PhD}$ dissertation. The behavioral aspects of $\mathrm{A}$. palliata foraging strategy and the pertinent ecological details of its habitat in Barro Colorado Island are most competently described and analyzed by Milton. She convincingly demonstrates that the mantled howler is a primary consumer of vegetable matter who selectively eats leaves (48.2\% of overall feeding time, and mostly of the young variety), fruits (42.1\%) and flowers $(9.6 \%)$ as each of these edibles becomes available seasonally in a number of plant species patchily distributed in the forest. The animal consumes leaves when there is less fruit - mostly in the transition from wet to dry season, and least in the dry; fruits are eaten when they are most available and preferentially in the morning feeding episodes, and flowers when available. A. palliata in Barro Colorado Island, however, feeds on fig trees (Ficus) throughout the year, taking advantage of the fact that individual Ficus trees undergo asynchronous phenological changes; the mantled howler thus finds young leaves, fruits and flowers in one or another of the fig trees at any moment.

Milton provides evidence to validate the opinion that in correlation with the energetic and physiologic characteristics of the vegetarian diet of the mantled howler in Barro Colorado Island, the behavioral aspects of their foraging strategy, and some of the other components of their conduct are geared toward the preservation of body energy, and when needed, toward assuring that the time-consuming digestion of the food ingested be completed with minimal interruptions. Thus, she correctly interprets the prehensile tail and its uses in Alouatta as an adaptation to increase the reach of the animals to aprehend food, and when considering the vocalizations of the howlers, Milton agrees with the generally held notion that these sounds are spacing signals. Milton then interprets the vocal mechanisms of howlers as part of its energy conservation adaptations. It is important to emphasize, in relation to the energy preservation trend of howlers, that Milton reports the mantled howlers of Barro Colorado Island as resting for $65.54 \%$ of their daylight time, a repose period which follows their foraging-feeding and/or travel activities. It is the opinion of Milton that a similar foraging strategy prevails in other species of Alouatta, some of which she has observed in Argentina (A. caraya), in Brazil (A. belzebul, A. fusca), and in Peru (A. seniculus).

Milton's efforts, as is evident from the content of her book, concentrated on the behavioral and ecological aspects of the howling monkey's foraging strategy, but she did Book Review 
not do much with the morphology of the animal that is involved in this strategy. She does not use, for example, the available information on the musculo-skeletal anatomy of howlers (A. caraya, A. seniculus), even if this morphological data is most relevant to the positional habits of these animals when foraging and eating. Her anatomical and physiological data about the digestive system is evidently limited by the dearth of information about this aspect of howler's biology. She is therefore restricted to relating the relative surface areas of different parts of the gastrointestinal tract in 24 primate species, including Alouatta, to the processing of toxins and of the abundant structural materials contained in the diet of A. palliata.

The book is a very solid contribution toward understanding the relations between behavior and habitat features in the foraging strategy of howlers, and the minor deficiencies noted above about the anatomo-physiological aspects of this strategy in Alouatta do not diminish the value of Milton's book. It must be read carefully by all those interested in the biology of this interesting genus, in that of the platyrrhines in general, and in the feeding mechanisms of mammals. This reviewer detected only one printing mistake: Chagras River instead of Chagres River. Miguel A. Schön Ybarra, San Juan, P.R. 